\title{
IDEOLOGIA BURGUESA E DOMINAÇÃO CAPITALISTA COMO MOVIMENTO CIENTÍFICO E POLÍTICO-FILOSÓFICO NA DIALÉTICA DO ESCLARECIMENTO
}

\section{BOURGEOIS IDEOLOGY AND DOMINATION CAPITALIST AS SCIENTIFIC AND PHILOSOPHICAL-POLITICAL MOVIMENT IN DIALECTICS ENLIGHTENMENT}

\author{
Océlio Jackson Braga* \\ Enéas Arrais Neto**
}

\section{RESUMO}

O presente artigo é uma reflexão a partir das contribuições de Adorno e Horkheimer na obra Dialética do Esclarecimento que investiga a ação ideológica da sociedade burguesa enquanto fenômeno histórico-social que surgiu no alvorecer do Século das Luzes. Discute-se em que sentido este movimento ideológico apropriou-se do pensamento científico para invalidar o pensamento metafísico e o saber crítico-filosófico posterior e de que modo se utilizou da ciência e a técnica como meros instrumentos da dominação da natureza e do homem pelo homem na roupagem de um projeto emancipatório que consolidou o sistema capitalista vigente. Busca-se compreender a crítica ao modus operandi da razão instrumental e a sua assimilação ideológica como movimento político-filosófico que utilizou o direito positivo, a arte e os meios de comunicação de massa para manter a organização social divida em classes sociais.

Palavras-chave: Razão Instrumental - Capitalismo - Ideologia - Alienação.

\section{ABSTRACT}

This article is a reflection from the contributions of Adorno and Horkheimer in Dialectic of Enlightenment work that investigates the ideological action of bourgeois society as social-historical phenomenon that emerged at the dawn of the Enlightenment. It discusses in what sense this ideological movement appropriated the scientific thought to invalidate the metaphysical thinking and critical-philosophical know later if and how the science and technology used as mere instruments of domination of nature and of man by man in the guise an

\footnotetext{
* Doutorando em Educação pela Universidade Federal do Ceará (UFC). Graduado em Filosofia pela UECE e Mestre em Educação pela UFC. Pesquisador do Laboratório de Estudos do Trabalho e Qualificação Profissional - LABOR/UFC. E-mail: jacksonbraga13@gmail.com

** Arquiteto, Mestre em Sociologia e Doutor em Educação pela Universidade Federal do Ceará (UFC). Email: eneas_arrais@hotmail.com
} 
emancipatory project that consolidated the capitalist system. We seek to understand the critique of instrumental reason modus operandi and their ideological assimilation as philosophical-political movement that used the positive law, art and mass media to maintain social organization divided into social classes.

Keywords: Instrumental Reason - Capitalism - Ideology - Alienation.

\section{INTRODUÇÃO}

No decorrer da modernidade, segundo Adorno e Horkheimer (1985), o modelo de racionalidade desenvolvido tornou-se com o avanço técnicocientífico e a produção de bens em grande escala, a fonte ideológica de afirmação do capitalismo, da divisão de classes e, principalmente, da exploração da classe trabalhadora. De acordo com Habermas (1987a), na obra Dialética do Esclarecimento (1947), encontramos elementos que nos permitem compreender melhor esse movimento da burguesia de consolidação do pensamento científico como um projeto político-filosófico de emancipação que levantou bandeiras de liberdade, de igualdade e de fraternidade nunca efetivadas na sociedade ocidental.

A obra, apesar de produzida em meio à divisão do mundo em dois blocos, do horror da II Guerra Mundial (1939-1945), de sistemas totalitários e da incerteza da liberdade e de um pretenso progresso que também tem conduzido a humanidade à barbárie, mantém sua atualidade na sociedade contemporânea ao denunciar como o pensamento crítico pode ser capturado, fragmentado e até distorcido pela ideologia dominante veiculada pelo que os autores chamaram de Indústria Cultural. ${ }^{1}$

Os frankfurteanos se defrontam com o objetivo de investigar o que chamam de autodestruição do Esclarecimento. Apesar de não terem dúvida de que a liberdade na sociedade é inseparável do pensamento iluminista ou

\footnotetext{
${ }^{1}$ Indústria Cultural é uma categoria do pensamento adorniano para criticar a dominação ideológica do sistema capitalista que utiliza os meios de comunicação social para tornar as pessoas em meros consumidores e para difundir as ideias da classe dominante. ADORNO, Theodor; HORKHEIMER, Max. Dialética do esclarecimento: fragmentos filosóficos. Rio de Janeiro: Jorge Zahar Editora, 1985, p. 80 ss.
} 
esclarecedor ${ }^{2}$ e de seus avanços científicos e tecnológicos, reconhecem com a mesma clareza que, o conceito desse novo modelo de racionalidade trás em si o germe da regressão. Consideram que há um elemento destrutivo no progresso: o pensamento cegamente pragmático como único meio de acesso a verdade conduziu a humanidade à barbárie. A disposição desse elemento "progresso" na organização social é encontrada na fascinação das massas educadas tecnologicamente para se deixar dominar pelo despotismo do poder econômico, o que revela a fragilidade e o pouco alcance do pensamento crítico junto à massa de trabalhadores. ${ }^{3}$

A famosa frase: "O progresso converte-se em regressão", revela como a razão instrumental promove o desenvolvimento econômico, as condições materiais para um mundo mais justo e, simultaneamente, se estabelece como a única forma possível de conhecimento arrastando a humanidade à barbárie, a autodestruição. Detentora do método científico, propagado como único capaz de produzir conhecimento seguro, a razão instrumental ao apodera-se do pensamento crítico, de base marxiana, tornando-o confuso em meio a uma enxurrada de informações planejadas, precisas e difundidas pelos meios de comunicação de massa. Desta forma, segundo Adorno e Horkheimer (1985, p. 12), nem o pensamento crítico escapa da ideologia, pois ao se valer da linguagem na tentativa de chegar à verdade é tratado como um saber de opiniões, não científico, e de interpretações complicadas e obscuras sobre fatos sociais. E, nesse sentido, há a afirmação da Indústria Cultural como instrumento poderoso utilizado para bombardeá-lo com diversões dispersivas que idiotizam as pessoas, desviando-as do foco das discussões sociais e as colocando a serviço da ordem existente como meros consumidores do sistema capitalista.

A denúncia da Escola de Frankfurt é que o Esclarecimento exprime com tenacidade o movimento real da sociedade burguesa encarnada em

\footnotetext{
${ }^{2}$ Os termos Iluminismo, Ilustração ou "ideal iluminista da burguesia" são utilizados neste artigo como Esclarecimento em função da tradução do original Aufkärung para designar não só a "Época das Luzes" ou a "filosofia dos pensadores iluministas" como uma época histórica determinada, mas o processo de "desencantamento do mundo" e de dominação do capitalismo por meio da razão instrumental. Cf. ADORNO, Theodor; HORKHEIMER, Max. Dialética do esclarecimento: fragmentos filosóficos. Rio de Janeiro: Jorge Zahar Editora, 1985, p. 7-8.
}

${ }^{3} I d .$, p. 13.

Revista LABOR

no 8, v.1, 2012

ISSN: 19835000 
pessoas e instituições que difundem a ideologia da dominação capitalista pelo discurso da neutralidade da ciência; do poder da técnica como forma de dominar as forças da natureza; e da política de libertar o homem das formas de escravidão contemporânea, o que de fato não ocorre. Os objetivos últimos desse projeto emancipatório-libertário da sociedade burguesa é falsa clareza; é mais um mito que se consolida na modernidade: o mito da razão instrumental como ideologia.

É importante ressaltar aos que trabalham com a formação da classe trabalhadora na perspectiva da emancipação social que, entre as instituições que reproduzem a ideologia do capital estão as instituições da educação principalmente aquelas vinculadas ao Estado, as escolas públicas - foram as primeiras a incorporar esse modelo de racionalidade. Ainda hoje têm no projeto libertário-iluminista a ciência e a técnica como instâncias de validade para instrumentalizar sua ação e preparar as novas gerações visando atender a demanda da sociedade e do mercado no exercício do progresso e do domínio das forças da natureza correspondendo muito pouco ao ideal dos frankfurteanos de contribuir com a formação crítica, sociopolítica e emancipatória que o nosso tempo exige (BRAGA, 2012).

\section{O PENSAMENTO CIENTÍFICO A SERVIÇO DA IDEOLOGIA BURGUESA}

No prefácio da Dialética do Esclarecimento, ao explicar a divisão da obra, denunciam Adorno e Horkheimer (1985, p. 15-16):

[...] o mito já é o esclarecimento e o esclarecimento acaba por reverter à mitologia. [...] a "indústria cultural" mostra a regressão do esclarecimento à ideologia, que encontra no cinema e no rádio sua expressão mais influente. O esclarecimento consiste aí, sobretudo, no cálculo da eficácia e na técnica de produção e difusão.

A eficácia, o método ou técnica, a produção e a difusão são características adequadas ao desenvolvimento do sistema capitalista que coordena o que os frankfurteanos chamaram de razão instrumental. Nela não há preocupação com a verdade, mas com o modus operandi, o procedimento eficaz. O que se espera é o resultado, o êxito. Diferentemente dos mitos antigos, o que importa não é o mistério, a revelação, inspirar as novas Revista LABOR no 8, v.1, 2012

ISSN: 19835000 
gerações ou agregar valor a cultura e ao convívio social, mas operar na natureza para prover a vida em troca do lucro. Este é o verdadeiro sentido da técnica como dominação: êxito é lucro para quem detém os meios de produção; eis o objetivo e a função da ciência na ordem do desenvolvimento capitalista. $^{5}$

A referência simbólica às três invenções: a imprensa, o canhão e a bússola; são exemplos clássicos do modo como a sociedade burguesa apropria-se do saber científico, dos meios de produção e dos meios de comunicação para manter-se no poder e concentrar a riqueza. A imprensa é o instrumento que tornou possível a difusão da ciência e da técnica; o canhão representa o domínio dos mais fortes sobre os mais fracos pela força das armas; a bússola, o instrumento que orientou a busca da riqueza, fomentou as grandes navegações e o comércio. A máxima baconiana saber como sinônimo de poder foi rapidamente compreendida no pensamento esclarecedor. Assim, para Adorno e Horkheimer (1985) seja o que for que a ciência descubra e domine só terá sentido se puder de alguma forma ser apropriado e reproduzido como procedimento eficaz com fins práticos a serviço do êxito da economia capitalista.

$\mathrm{Na}$ investigação dos frankfurteanos, o trajeto das ciências modernas é marcado pela crítica ao pensamento metafísico - chamado de razão objetiva - e a qualquer outro saber filosófico sobre a sociedade dividida em classes para substituí-los pelo conceito da fórmula e das regras probabilísticas. Todo sentido que se possa dar ao fato social é especulação; o que não pode ser provado pelo método científico é interpretação; animismo. Segundo Oliveira (2002, p. 63), significa dizer que a razão objetiva, a partir da modernidade, não é mais a ordem das coisas existentes no mundo (racionalidade metafísica), mas única e exclusivamente a solução de problemas a que chegamos somente mediante procedimentos corretos da razão (subjetivo-instrumental) para lidar com a realidade.

No ilusório discurso esclarecedor cabe à razão a missão de desencantar o mundo e libertar o homem das crenças e superstições que herdou das tradições culturais. Mas, segundo os autores da Dialética do 
Esclarecimento, tão nobre missão parece cegar aqueles que a empreendem. $O$ excesso de confiança no pensamento científico impele os "esclarecidos" a colocar a ciência moderna no patamar de uma deusa do conhecimento. Por isso, a perfeição cultuada em seus métodos e fins merece o mesmo desprezo que o pré-socrático Xenófanes dedicou aos deuses gregos e aos homens que os cultuavam. Ele zombava da multiplicidade de divindades, porque eram cheios de imperfeições iguais aos homens, contingentes e maus. Da mesma forma, só isolada do seu contexto histórico e elevada aos céus é que se pode falar de perfeição na ciência. Se apreciada no conjunto das relações sociais: da divisão de classes; do trabalho alienado; da manipulação política e midiática; saltam aos olhos suas reais imperfeições.

Assim, longe de libertar o homem, acorrenta-o e o conduz no caminho da autodestruição como revela a barbárie das duas guerras mundiais. $\mathrm{Na}$ perspectiva da Teoria Crítica da Escola de Frankfurt, a aparente neutralidade do pensamento científico é a pior de suas imperfeições, uma vez que, esconde as verdadeiras intenções de dominação da sociedade capitalista. Ela é que está por trás de seus métodos de eficiência e eficácia aplicados rigorosamente no uso da propriedade privada; dos meios de produção; e na exploração da força de trabalho da classe operária.

A pretensão da ciência de se tornar a porta-voz do que é e não é a verdade e de como ela deve ser descoberta (método científico), fez com que o pensamento crítico declarasse o movimento esclarecedor como um movimento totalitário. ${ }^{6}$ Porque o modelo de racionalidade que considerou o legado platônico e aristotélico que fundamentou o pensamento metafísico como incapaz de levantar pretensões de verdades universais é o mesmo que, contraditoriamente, arvora o direito de declarar que somente há cientificidade no saber esculpido com o cinzel da razão instrumental nas mãos dos cientistas da natureza. Os frankfurteanos ironizam ao questionar se, por acaso, essa afirmativa não seria uma declaração de uma "verdade universal". Para eles, a contradição está no fato de ser a própria ciência que declarou não serem possíveis verdades universais.

${ }^{6} I d .$, p. 23. 
Na concepção da Teoria Crítica, a ciência é uma produção histórica do pensamento tão falível quanto o homem que a criou. A desconstrução da ideologia do pensamento científico como único saber seguro é apresentada, segundo Habermas (1987b, p. 497) com uma abordagem mimética por Adorno e Horkheimer, para mostrar de forma alegórica, baseada nos mitos antigos, que é o homem e não o método o responsável pelo conhecimento produzido. $\mathrm{E}$ este, por usa vez, pode ser perfeitamente manipulado para fins de dominação. Um exemplo é a relação que o Esclarecimento estabelece para compreensão dos bens produzidos pela conhecimento técnico-científico no sistema capitalista. ${ }^{7}$ A relação pode ser comparada a mesma que os deuses gregos estabeleceram com os homens no mito da entrega da natureza nas mãos do homem-dominador. Não citam, mas o mito grego é semelhante ao mito judaicocristão da criação em que o homem recebe a primazia sobre todas as criaturas para dominar sobre elas. A conclusão dos frankfurteanos é que o homem de ciência toma para si a ordem dos deuses: dominar a natureza. Contudo, a partir daí não há mais deuses a quem prestar contas. A ciência moderna é a própria divindade; o fim último de si mesma. Assim como os magos tinham a ambição de realizar rituais para influenciar e usufruir das riquezas da natureza, o homem da ciência também prepara seus rituais metódicos para controlar as forças natureza. Todavia, diferentemente do mito, sua ação é sem cortinas, sem mistérios, mas esconde a ideologia da sociedade burguesa nos resultados que colhem pela apropriação dos bens produzidos e pela exploração dos trabalhadores que as produziram.

Para o movimento do esclarecimento o pensamento científico parte do princípio de que não há nenhum sentido na natureza a não ser o que o próprio homem Ihe emprega. Contudo, segundo a perspectiva da Teoria Crítica, na relação sujeito-objeto tanto o sujeito altera o objeto como o objeto altera o sujeito, de tal maneira que, o preço pago pelo poder recebido - de senhores absolutos da natureza - é a alienação de si (MARX, 1963). O exemplo é tomado pelos autores da Dialética do Esclarecimento das tradições míticas, na ação do feiticeiro que molda seus rituais para o exercício da cura.

\footnotetext{
${ }^{7} I d$., p. 23. ADORNO, Theodor; HORKHEIMER, Max. Dialética do esclarecimento: fragmentos filosóficos. Rio de Janeiro: Jorge Zahar Editora, 1985, p. 23.
} 
Seu ofício é uma alusão à ação de dominação da natureza que encerra a promessa de libertação do homem. Em sua ação mágica, ao prometer a libertação do mal, o feiticeiro emprega todo esforço para expulsar ou acalmar os demônios. Durante os rituais, ele acaba imitando os demônios e espíritos de tal maneira que se confunde com aquilo que tenta dominar. Da mesma forma, a ciência funcional, metódica, nada mais é que o ritual de dominação da natureza e do homem pelo homem. Nos processos e métodos empregados pela razão instrumental, natureza e homem são propositalmente confundidos. E longe de liberar, o Esclarecimento, como movimento da sociedade burguesa, acabou por escravizar os homens no seu projeto de desencantamento do mundo, transformando tudo o que vê na natureza em mercadoria, inclusive o próprio homem:

O preço dessa vantagem, que é a indiferença do mercado pela origem das pessoas que nele vêm trocar suas mercadorias, é pago por elas mesmas ao deixarem que suas possibilidades inatas sejam modeladas pela produção das mercadorias que se podem comprar no mercado. (ADORNO; HORKHEIMER, 1985, p. 27).

Dessa forma, dominação e trabalho se separam aparentemente no Esclarecimento imitando velhas práticas de tirania; e não diferem muito dos reis da Antiguidade. No exemplo de Adorno e Horkheimer (1985, p. 30), a ação estratégica dos patrícios consistia em invadir terras vizinhas, colocar no árduo trabalho do campo os incultos e cercar-se dos médicos, adivinhos, artesãos e comerciantes para garantir a vida social e reproduzi-la na cultura e na educação das novas gerações. Na perspectiva da Dialética do Esclarecimento, o mito de Ulisses é o exemplo perfeito da ação ideológica empregada pelos capitalistas no exercício de aplicação da ciência e da técnica na dominação da natureza e do homem pelo homem. Mesmo à distância, Ulisses - personagem da Odisseia - controlava um numeroso pessoal, meticulosamente organizado em grupos de servidores, pastores e guerreiros. Ao anoitecer, podia contemplar do alto de seu palácio suas terras iluminadas pelas fogueiras dos servidores que vigiavam com diligência as riquezas que produziam, mas que não lhes pertencia. Assim, a ciência e a técnica permanecem nas mãos do capitalista como instrumento para dominar a natureza, mas só aparentemente, pois, de fato, quem realiza a ação são os trabalhadores organizados em diferentes 
funções. No mito do Esclarecimento, o trabalho alienado, a divisão de classes, a Indústria Cultural, a uniformização da coletividade continuam sobre as roupagens modernas a dominação da sociedade burguesa.

\section{A IDEOLOGIA BURGUESA COMO MOVIMENTO POLÍTICO E FILOSÓFICO CONSOLIDADO PELO DIREITO E PELA INDÚSTRIA CULTURAL}

Merece destaque em nossa reflexão, o exemplo da organização social dominada politicamente pela burguesia explicada de forma alegórica na Dialética do Esclarecimento na passagem da Odisseia em que o navio de Ulisses se aproxima das Sereias. ${ }^{8}$ A condição dos servos e a de Ulisses é a condição da classe trabalhadora e da classe burguesa; dos operários da fábrica e dos seus patrões. Para que não se atirassem ao mar ao som encantado das Sereias, os servos tinham os ouvidos tapados e deviam olhar para frente e remar incansavelmente. Ulisses, por sua vez, para usufruir do canto sedutor, delegou o comando do navio a um imediato e ordenou que 0 amarrassem no mastro, ao centro. A substituibilidade é uma prerrogativa da classe burguesa que delega funções a subalternos e desfruta do tempo livre e das ocupações do trabalho. Aos trabalhadores, permanece a ilusão de olhar sempre para frente com os ouvidos moucos sem poder comunicar-se. A dominação do corpo, o controle dos sentidos, do que ouve, do que vê são indícios da alienação. Permanece o mito de que se todos estiverem livres a desordem afundará o navio social. Portanto, o domínio da técnica, do progresso e da administração das massas no conformismo do trabalho alienado, constituem dois aparatos lógicos mediados pela política e pela ciência do modus operandi da razão subjetivo-instrumental para se perpetuar como sistema econômico do capital.

No campo filosófico e moral, segundo os frankfurteanos, a racionalidade em Descartes, Leibniz e Kant, expoentes do Esclarecimento, foi utilizada com a finalidade de levar a cabo a conexão sistemática dos conhecimentos a partir de um princípio ou leis para subir aos gêneros superiores como descer às espécies inferiores da natureza a fim de que

${ }^{8} I d .$, p. $45-47$.

Revista LABOR

no 8, v.1, 2012

ISSN: 19835000 
fundarem o método científico e se tornarem senhores da verdade. Trata-se da produção de uma "ordem científica unitária" dona da verdade da qual pudessem derivar conhecimentos provenientes da experiência e arquitetados em axiomas arbitrariamente escolhidos a partir de ideias inatas ou de abstrações, ou de hipóteses, ou mesmo de observações. Na ascensão da burguesia na Era das Luzes, uma manobra semelhante também foi realizada no campo da moral com base na filosofia kantiana. ${ }^{9}$

A crítica é dirigida especialmente ao filósofo Immanuel Kant (17241804) por não perceber a ideologia escondida no movimento da razão subjetiva ao declarar que o Esclarecimento "[...] é a saída do homem da menoridade, da qual é o próprio culpado". ${ }^{10}$ Os frankfurteanos interpretam que a menoridade é a incapacidade de se servir do entendimento, e seguir sob a direção de outrem. Apoiado na filosofia kantiana, o pensamento esclarecedor da burguesia apresenta-se como o novo tutor do conhecimento e da moral social e realiza a inversão do saber colocando o entendimento ou o saber crítico sob a tutela da razão instrumental. Como explicitamos, para Adorno e Horkheimer (1985), a ciência é aplicação, é técnica a serviço da autoconservação, objetivamente usada para produzir bens de troca e uma massa de consumidores. Contudo, a mesma razão como instrumento de dominação do homem pelo homem, é na modernidade aplicada dentro de um sistema bem arranjado na área da moral: o uso do direito natural e das leis para controlar as massas.

A nova proposta, de racionalizar o direito, tem o objetivo de substituir as tradições morais e as leis religiosas sem, no entanto, alterar a condição econômica e política nem os reais interesses de prestígio da classe dominante. Explicam Adorno e Horkheimer (1985, p. 83): "O burguês nas figuras sucessivas do senhor de escravos, do empresário livre e do administrador é o sujeito lógico do esclarecimento".

A ideia tem sua fundamentação nos conceitos kantianos considerados ambíguos quando utilizados pelo Esclarecimento. As categorias da Crítica da Razão Pura (1781) são rebaixadas à relação obscura entre "ego transcendental" como Razão Pura e "ego empírico" como Razão Prática e ambas fundadas na falsa ideia de liberdade, uma vez que pensamento e

\footnotetext{
${ }^{9}$ Id., p. 81.

${ }^{10}$ KANT, 1784 apud ADORNO; HORKHEIMER, 1985, p. 52.

Revista LABOR

$\mathrm{n}$ ㅇ 8, $\mathrm{v} .1,2012$
}

ISSN: 19835000 
natureza constituem, no capitalismo, uma relação de exploração do homem que transforma a matéria em objeto com uma finalidade prática: o lucro. Assim, também, as categorias de universal e particular são harmonizadas no esquematismo lógico das leis para garantir a autoconservação e o direito de explorar em qualquer parte, segundo os interesses da sociedade industrial. A generalização do homem e da natureza como objetos da ciência segue uma lógica democrática de igualdade: diante da ciência tudo é objeto de estudo, inclusive o próprio homem. Os "conceitos de razão" extraídos da obra de Kant escondem a exploração na divisão de classes e preparam, no terreno da moral, o controle social mediante as leis civis do Estado burguês:

\begin{abstract}
A ciência ela própria não tem consciência de si, ela é um instrumento, enquanto o esclarecimento é a filosofia que identifica a verdade ao sistema científico. [...] Com a confirmação do sistema científico como figura de verdade - confirmação essa que é um resultado da obra de Kant - o pensamento sela sua própria nulidade, pois a ciência é um exercício técnico, tão afastado de uma reflexão sobre seus próprios fins como o são as outras formas de trabalho sob a pressão do sistema. (ADORNO; HORKHEIMER, 1985, p. 27).
\end{abstract}

No âmbito da moral, o Esclarecimento intentou substituir a religião pelo agir moral racional. O objetivo era "[...] derivar de uma lei da razão o dever do respeito mútuo". ${ }^{11}$ Esse agir moral racional deveria estar atrelado à coação da lei, à força do sistema jurídico, como forma de regular a conduta das massas e proteger a propriedade privada. O que se intenta com o novo projeto moral é substituir o medo supersticioso dos castigos do inferno futuro pelo pavor quimérico das punições legais. ${ }^{12}$ Mas é somente sobre o povo que recai o pesa da lei; o rico capitalista nada deve temer, pois sob a égide da Razão Instrumental tem agora o caminho aplainado pela ordem rumo ao progresso pela força da lei - já que qualquer insurreição da classe trabalhadora é considerada transgressão da lei e da ordem social. Trata-se, no fundo, de uma medida de proteção da classe dominante que tem medo da organização e da revolta da classe trabalhadora. Noutras palavras, o medo da sociedade burguesa é o medo da autoconsciência da classe trabalhadora e de sua

\footnotetext{
${ }^{11} I d .$, p. 85 .

${ }^{12} I d .$, p. 86.
}

Revista LABOR 
revolta. Nesse sentido explicam Adorno e Horkheimer (1985, p. 27) referindose ao período inicial da Revolução Industrial:

Os dirigentes estavam dispostos a proteger o mundo burguês contra o oceano da violência aberta que realmente assolou a Europa, apenas enquanto a concentração econômica ainda não havia progredido suficientemente. (ADORNO; HORKHEIMER, 1985, p. 27).

Aliada a moral racionalizada pelo direito positivo, a economia de mercado desencadeou os processos de produção que potencializaram o domínio da racionalidade instrumental sobre a falsa ideia de "homens livres e iguais diante da lei". Seguir a lei é manter a "ordem para o progresso"; isto é, a ordem de comando da classe dominante sobre os que devem fazer 0 progresso pela força do trabalho alienado, a classe trabalhadora (MARX, 1963).

Se o Esclarecimento armou-se com a ciência e a técnica para desbancar a metafísica; revestiu-se da filosofia kantiana, da força da lei e do sistema jurídico para controlar as massas; da dinâmica do mercado potencializado pela economia liberal para maximizar os lucros. Restou-lhe, por fim, o cuidado de difundir suas ideias e valores como sendo "as ideias e valores da vida moderna", comum a todas as classes sociais. Essa difusão tornou-se mais um instrumento de dominação que os frankfurteanos chamaram de Indústria Cultural: o cinema, o rádio, a televisão, as revistas constituem juntos um sistema de controle, no qual, a verdade ou a arte que veiculam não passam de um negócio; e eles o utilizam como "[...] ideologia destinada a legitimar o lixo que propositalmente produzem". ${ }^{13}$ Os métodos tecnológicos sobre os quais repousa essa ideologia são a reprodução e a padronização do consumo pelas massas; seu motor propulsor é a economia capitalista, a racionalidade da própria dominação. A passagem do uso do telefone para o rádio é um exemplo da falsa liberdade de escolha na sociedade capitalista e do controle social pelos meios de comunicação:

Liberal, o telefone permitia que os participantes ainda desempenhassem 0 papel do sujeito. Democrático, 0 rádio transformou-os a todos igualmente em ouvintes, para entregá-los autoritariamente aos programas, iguais uns aos outros [...] e as

${ }^{13} I d$., p. 114.

Revista LABOR

nㅇ 8, v.1, 2012

ISSN: 19835000 
emissões privadas são submetidas ao controle. (ADORNO; HORKHEIMER, 1985, p. 115-116).

Nesse sentido, o entretenimento, o lazer e a arte são esquematicamente colocados dentro de uma nova cadeia produtiva para serem controlados, estereotipados e transformados em produtos padronizados de consumo, e o mundo inteiro é forçado a passar pelo filtro da Indústria Cultural. A lógica de dominação do sistema capitalista pelos meios de comunicação tem o objetivo de fortalecer a lógica de subordinação vivenciada pelo trabalhador na atividade produtiva: a finalidade é "ocupar os sentidos dos homens da saída da fábrica, à noitinha, até a chegada ao relógio do ponto, na manhã seguinte". ${ }^{14} \mathrm{O}$ controle ideológico pela diversão é uma ação estratégica para intercalar na insatisfação do trabalho alienado um padrão de comportamento conformista que facilite a adaptação ao modelo administrativo racional da sociedade.

\section{CONSIDERAÇÕES FINAIS}

A racionalidade instrumental, na perspectiva da Teoria Crítica dos pensadores da Escola de Frankfurt, é impulsionada pela economia liberal e é assimilada como ideologia pela sociedade burguesa quando esta se organiza como movimento político para instaurar uma nova ordem: o sistema capitalista baseado na produção de mercadorias e na exploração da classe trabalhadora.

O Esclarecimento, enquanto fenômeno da sociedade burguesa, constitui-se como ação ideológica ao se apropriar do pensamento científico para invalidar o saber crítico-filosófico e utilizar a ciência e a técnica como meros instrumentos da dominação da natureza e do homem pelo homem na roupagem de um projeto emancipatório que longe de libertar a humanidade passou a explorar a mão de obra dos trabalhadores na produção de riqueza. Apesar do atual desenvolvimento tecnológico e da melhoria de vida, a riqueza, o poder político e econômico continua concentrado nas mãos da classe dominante.

A dominação ideológica dos donos do capital historicamente se consolida com a produção e o consumo alienados, com o modus operandi da

${ }^{14} I d .$, p. 123.

Revista LABOR

no 8, v.1, 2012

ISSN: 19835000 
razão instrumental baseado na ciência e na técnica e pelo movimento políticofilosófico que se utilizou do direito positivo, da arte e dos meios de comunicação de massa para manter a organização social divida em classes sociais.

\section{REFERÊNCIAS}

ADORNO, Theodor; HORKHEIMER, Max. Dialética do esclarecimento: fragmentos filosóficos. Rio de Janeiro: Jorge Zahar Editora, 1985. Disponível em: <http://adorno.planetaclix.pt/d e conceito.htm.pdf.>. Acesso em: 13 nov. 2011.

BRAGA, O. Jackson. EDUCAÇÃO, RACIONALIDADE E EMANCIPAÇÃO EM HABERMAS: implicações e contribuições do agir comunicativo na cultura organizacional escolar. 2012. 103 f. Dissertação (Mestrado em Educação) Faculdade de Educação, Universidade Federal do ceará, 2012.

HABERMAS, Jürgen. Teoria de la accion comunicativa: racionalidade de la acción y racionalización social. Tomo I. Madri: Taurus, 1987a.

Teoria de la accion comunicativa: crítica de la razón funcionalista. Tomo II. Madri: Taurus, 1987b.

Kant, Immanuel. Resposta à pergunta: "Que é esclarecimento?". In: Textos seletos. 3. ed. Petrópolis (RJ): Ed. Vozes, 2005.

MARX, K. Manuscritos econômicos - filosóficos. Lisboa: Edições 70, 1963.

OLIVEIRA, Manfredo Araújo de. Para além da fragmentação: pressupostos e objeções da racionalidade dialética contemporânea. São Paulo: Loyola, 2002. 